\title{
Influenza C Virus in Cattle with Respiratory Disease, United States, 2016-2018
}

\author{
Hewei Zhang, Elizabeth Porter, Molly Lohman, \\ Nanyan Lu, Lalitha Peddireddi, Gregg Hanzlicek, \\ Douglas Marthaler, Xuming Liu, Jianfa Bai
}

We identified influenza C virus (ICV) in samples from US cattle with bovine respiratory disease through real-time PCR testing and sequencing. Bovine ICV isolates had high nucleotide identities $(\approx 98 \%)$ with each other and were closely related to human ICV strains ( $\approx 95 \%)$. Further research is needed to determine bovine ICV's zoonotic potential.

I nfluenza viruses are contagious zoonotic pathogens that belong to the Orthomyxoviridae family, which consists of 4 genera: Alphainfluenzavirus (influenza A virus), Betainfluenzavirus (influenza B virus), Gammainfluenzavirus (influenza C virus [ICV]), and Deltainfluenzavirus (influenza D virus) (1-4). Classification of influenza viruses is based on the antigenic differences in the nucleoprotein and matrix protein and supported by intergenic homologies of $20 \%-30 \%$ and intragenic homologies $>85 \%$ (3).

The most common influenza pathogen is influenza $\mathrm{A}$ virus, which can infect humans, pigs, cattle, birds, as well as other animals $(2,4)$. ICV was first identified in humans in 1947. This group of influenza viruses was initially thought to exclusively infect humans until isolates were identified in pigs in China (5,6) and Japan (7). Antigenic and genetic analyses suggest that ICV might transmit between humans and pigs in nature (8); however, interspecies transmission has not been confirmed experimentally. In 2011, an influenza $\mathrm{C}$-like virus was identified in swine and cattle in the United States (9); this virus was initially proposed to be an ICV subtype but was later identified as influenza D virus (3) because the virus had $\approx 50 \%$ overall amino acid identity with human ICV strains, a level of divergence similar to that between influenza A and influenza B viruses.

Although influenza viruses of other genera can infect cattle, the potential for ICV infection in cattle has not been previously investigated. The objective of this study

Author affiliations: Chinese Academy of Agricultural Sciences, Institute of Special Economic Animal and Plant Sciences,

Changchun, China ( $H$. Zhang); Kansas State University Veterinary

Diagnostic Laboratory, Manhattan, Kansas, USA ( $H$. Zhang,

E. Porter, M. Lohman, N. Lu, L. Peddireddi, G. Hanzlicek,

D. Marthaler, X. Liu, J. Bai)

DOI: https://doi.org/10.3201/eid2410.180589 was to determine if ICV can be found in specimens from cattle with bovine respiratory disease and, if so, determine the prevalence.

\section{The Study}

Bovine respiratory disease complex (BRDC) is one of the most common causes of death in livestock in US feedlots and feedlots worldwide (10). During October 2016-January 2018, we collected 1,525 samples (mainly nasal swab and lung tissue specimens) from cattle in the Midwest of the United States and submitted them to Kansas State Veterinary Diagnostic Laboratory (Manhattan, Kansas, USA) for BRDC diagnostic testing. We screened samples for ICV by real-time reverse transcription PCR, as well as for 10 other BRDC-associated pathogens (Mannheimia haemolytica, Pasteurella multocida, Histophilus somni, Bibersteinia trehalosi, Mycoplasma bovis, bovine viral diarrhea virus, bovine respiratory syncytial virus, bovine respiratory coronavirus, bovine herpesvirus 1 , and influenza D virus; online Technical Appendix, https://wwwnc.cdc.gov/EID/ article/24/10/18-0589-Techapp1.pdf). We sequenced a 590-bp fragment of the matrix gene from $12 \mathrm{ICV}$-positive samples (GenBank accession nos. MH421865-73; online Technical Appendix Table) to confirm the PCR results and perform a phylogenetic analysis. We selected 1 isolate $(\mathrm{C} /$ bovine/Montana/12/2016) for complete genome sequencing (GenBank accession nos. MH348113-9).

Of 1,525 samples, $64(4.20 \%)$ were positive for ICV: 38 samples with a cycle threshold $\left(\mathrm{C}_{\mathrm{t}}\right)<36$ and 26 with a $\mathrm{C}_{\mathrm{t}}$ 36-39. The most common pathogens were bovine respiratory coronavirus $(34.98 \%), M$. bovis $(32.27 \%)$, and $M$. haemolytica (17.04\%). The remaining BRDC pathogens were present but less prevalent: P. multocida (13.42\%), H. somni (12.58\%), influenza D virus (11.93\%), bovine respiratory syncytial virus $(9.19 \%)$, bovine viral diarrhea virus $(7.05 \%)$, B. trehalosi $(3.47 \%)$, and bovine herpesvirus $1(2.95 \%)$.

Co-infections with $\geq 1$ pathogen are common in BRDC cases. ICV-positive samples were also found to be positive for $\geq 1$ bovine respiratory disease pathogen $(\mathrm{n}=12$, Table 1), the most common being M. bovis (9/12), followed by $H$. somni (7/12), and M. haemolytica (6/12). Among the ICVpositive samples, ICV12 was strongly positive $\left(\mathrm{C}_{t} 15.81\right)$; this sample was also positive for M. haemolytica and $P$. multocida, both bacterial pathogens commonly associated with secondary infections. Other BRDC pathogens associated 
Influenza C Virus in Cattle, United States

Table 1. Cycle thresholds for ICV and other bovine respiratory pathogens in 12 ICV strong positive samples from cattle with respiratory disease, United States, October 2016-January 2018*

\begin{tabular}{|c|c|c|c|c|c|c|c|c|c|c|c|c|}
\hline ID no. & State & ICV & BVDV & BHV-1 & BRSV & BCoV & IDV & $\begin{array}{c}\text { Mycoplasma } \\
\text { bovis }\end{array}$ & $\begin{array}{l}\text { Mannheimia } \\
\text { haemolytica }\end{array}$ & $\begin{array}{c}\text { Pasteurella } \\
\text { multocida }\end{array}$ & $\begin{array}{c}\text { Histophilus } \\
\text { somni }\end{array}$ & $\begin{array}{c}\text { Bibersteinia } \\
\text { trehalosi }\end{array}$ \\
\hline ICV1† & TX & 29.95 & - & - & - & - & 36.77 & 39.41 & - & - & - & - \\
\hline ICV2† & OK & 23.92 & - & - & - & - & 24.25 & 29.17 & 31.30 & - & 31.32 & - \\
\hline ICV3† & OK & 21.02 & - & - & 38.93 & 27.00 & 29.15 & 31.40 & NT & NT & NT & NT \\
\hline ICV4‡ & OK & 29.98 & - & - & - & - & - & 24.54 & 31.33 & - & 31.05 & - \\
\hline ICV5† & MO & 24.47 & - & 34.98 & - & - & - & 30.12 & - & 28.00 & 24.40 & 34.00 \\
\hline ICV6† & $\mathrm{CO}$ & 26.91 & - & - & - & - & - & 30.25 & 32.78 & 29.60 & 30.00 & 35.00 \\
\hline ICV12† & MT & 15.81 & - & - & - & - & - & - & 22.87 & 25.70 & - & - \\
\hline ICV16ł & NE & 27.18 & 16.44 & - & - & - & - & 28.47 & - & - & - & - \\
\hline ICV18† & MN & 30.58 & - & - & - & - & - & - & 35.06 & - & - & - \\
\hline ICV20‡ & KS & 27.92 & - & - & - & - & - & - & - & - & 23.49 & - \\
\hline ICV21† & $\mathrm{KS}$ & 26.72 & - & - & 35.59 & - & - & 25.67 & 30.95 & - & 28.47 & - \\
\hline ICV22† & MT & 25.08 & - & - & - & - & 20.24 & 35.58 & - & - & 35.64 & - \\
\hline
\end{tabular}

with secondary infections (M. bovis, bovine viral diarrhea virus, and $H$. somni) were also detected in samples ICV4, ICV16, ICV18, and ICV20 (11-13). These results suggest that ICV is associated with bovine respiratory disease in cattle.

We further evaluated 12 strong positive $\left(\mathrm{C}_{\mathrm{t}}<31\right)$ samples by sequencing a 590-bp fragment of their matrix gene. Alignment of the partial matrix gene sequences indicated that the isolates in 3 samples (ICV2, ICV3, and ICV4) obtained from different cattle on the same farm in Oklahoma were identical. Because these 3 influenza viruses were most likely the same strain, the virus in just 1 sample (ICV2) was used for phylogenetic analysis. The matrix gene sequence in sample ICV5 from Missouri (GenBank accession no. MH421866) was identical to that in ICV6 from Colorado (GenBank accession no. MH421867).

Phylogenetic analysis indicated that the bovine ICV isolates are closely related to the porcine and human ICV isolates, and the bovine ICV isolates are more closely related to each other (Table 2; Figure). The bovine ICV isolates' partial matrix gene sequences shared high nucleotide identities $(\approx 98 \%)$. For both partial matrix gene sequences and the whole genome sequence (7 segments), the nucleotide identity between bovine and human isolates was $\approx 95 \%$. The full genome sequence of $\mathrm{C} /$ bovine/Montana/12/2016 from sample ICV12 had high nucleotide identity to C/Mississippi/80 (and several other human ICV strains), with an overall identity of $97.1 \%$. Nucleotide identities between these 2 isolates were also high for each gene: $97.0 \%$ for polymerase basic $2,97.7 \%$ for polymerase basic $1,97.5 \%$ for polymerase 3, 96.2\% for hemagglutinin esterase, $96.8 \%$ for nucleoprotein, $96.8 \%$ for matrix, and $97.6 \%$ for nonstructural protein. The only porcine ICV isolate available was more closely related to human $(\approx 98 \%$ identity) isolates than bovine $(\approx 95 \%$ identity) isolates; the porcine ICV isolate had nearly the same identity that the human ICV isolates had among each other (Table 2).

The phylogenetic tree of the partial matrix gene sequences (Figure) further demonstrates the relationship between bovine and human ICV isolates. All bovine ICVs formed a separate clade on the phylogenetic tree, with a $99 \%$ bootstrap value. Of the 195 partial matrix gene sequences from human ICVs, the 10 corresponding sequences from bovine ICVs had the highest identities (average $96.70 \%$ ) to those from C/Mississippi/80 (GenBank no. AB000720.1), C/Nara/82 (GenBank no. AB000723), and $\mathrm{C} / \mathrm{Kyoto} / 41 / 82$ (GenBank no. AB000724) and the lowest identities (average $94.21 \%$ ) to those from $\mathrm{C} / \mathrm{Ya}$ magata/30/2014 (GenBank no. LC123874) and C/Yamagata/32/2014 (GenBank no. LC123875).

\begin{tabular}{|c|c|c|c|c|c|}
\hline Gene sequence & Bovine ICV, \% & Human ICV, \% & $\begin{array}{l}\text { Bovine ICV vs. } \\
\text { human ICV, \% }\end{array}$ & $\begin{array}{l}\text { Bovine ICV vs. } \\
\text { porcine ICV, \% }\end{array}$ & $\begin{array}{l}\text { Human ICV vs. } \\
\text { porcine ICV, \% }\end{array}$ \\
\hline Matrix, partial & 98.43 & 98.47 & 95.54 & 96.06 & 98.84 \\
\hline Polymerase basic 2 & NA & 97.76 & 94.97 & 95.00 & 98.34 \\
\hline Polymerase basic 1 , full length & NA & 97.59 & 94.69 & 94.70 & 98.08 \\
\hline Polymerase 3 & NA & 97.79 & 96.36 & 95.50 & 97.31 \\
\hline Hemagglutinin esterase & NA & 95.44 & 90.83 & 91.10 & 95.97 \\
\hline Nucleoprotein & NA & 97.67 & 95.48 & 95.30 & 97.85 \\
\hline Matrix, complete & NA & 98.33 & 95.51 & 95.80 & 98.82 \\
\hline Nonstructural protein & NA & 98.32 & 95.67 & 95.80 & 98.36 \\
\hline Entire genome & & 97.56 & 94.79 & 94.74 & 97.82 \\
\hline
\end{tabular}

${ }^{*} \mathrm{ICV}$, influenza C virus; NA, not applicable. 


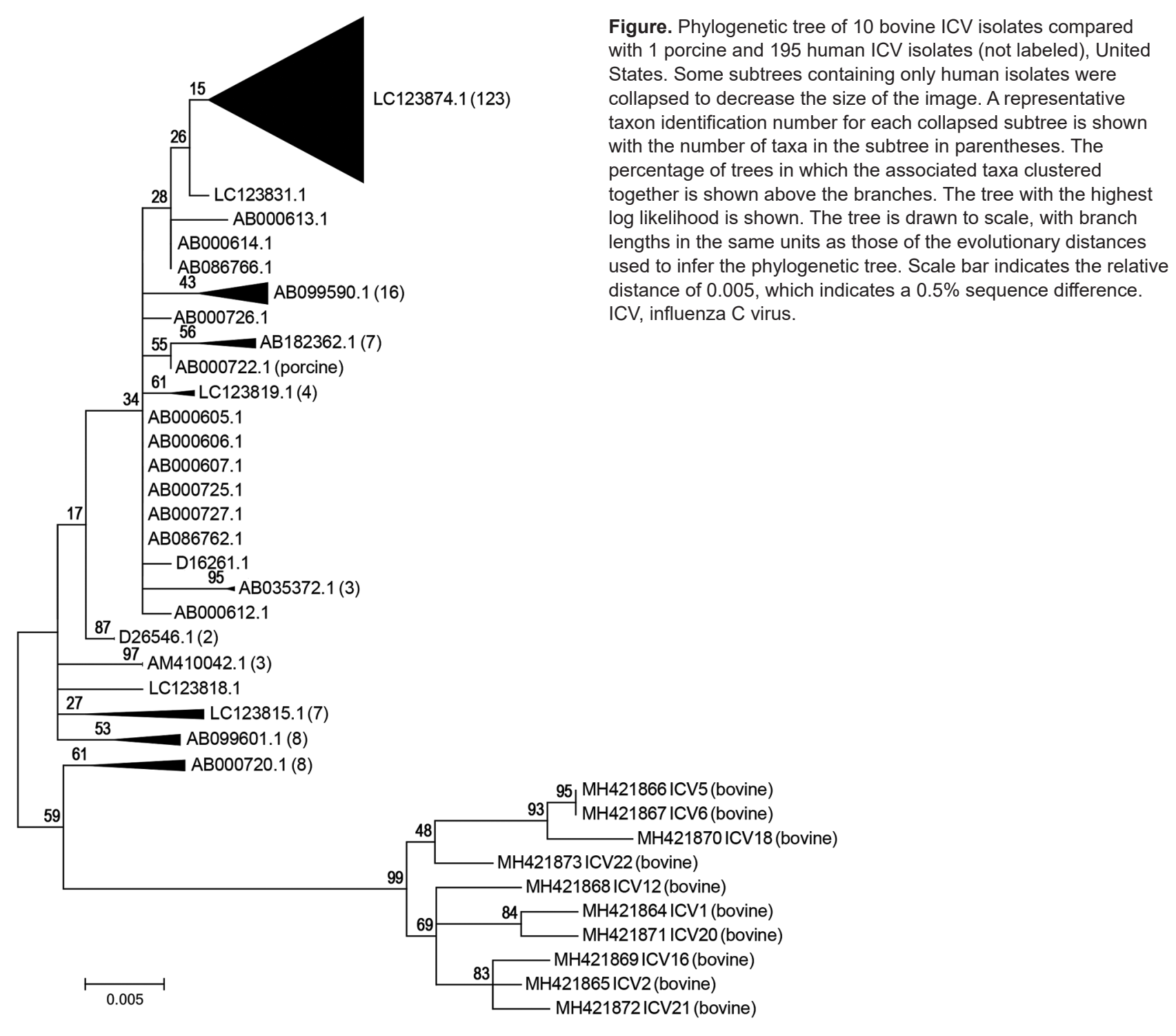

Figure. Phylogenetic tree of 10 bovine ICV isolates compared with 1 porcine and 195 human ICV isolates (not labeled), United States. Some subtrees containing only human isolates were with the number of taxa in the subtree in parentheses. The percentage of trees in which the associated taxa clustered together is shown above the branches. The tree with the highest log likelihood is shown. The tree is drawn to scale, with branch engths in the same units as those of the evolutionary distances distance of 0.005 , which indicates a $0.5 \%$ sequence difference. $\mathrm{CV}$, influenza $\mathrm{C}$ virus.

\section{Conclusions}

This study confirms the presence of ICV in US cattle with clinical signs of bovine respiratory disease. Although interspecies transmission of influenza viruses occurs between humans and other animals, we do not have data that indicates ICV is a zoonotic pathogen. However, the full genome sequence of $\mathrm{C} /$ bovine/Montana/12/2016 has $97.1 \%$ nucleotide identity with the human isolate C/Mississip$\mathrm{pi} / 80$, which is within the range of average identities among human isolates. More detailed investigations are needed to confirm if ICV is involved in bovine respiratory disease, to characterize the relationship between bovine and human ICV strains, and to determine the zoonotic potential of bovine ICV isolates to cause human disease.

Funding for this study was provided by the Kansas State Veterinary Diagnostic Laboratory and the Swine Health Information Center.

\section{About the Author}

Mr. Zhang is a joint doctoral student candidate at the Chinese Academy of Agricultural Sciences in Changchun, China, and Kansas State University in Manhattan, Kansas, USA. His research interests are the development and validation of molecular diagnostic assays for animal and zoonotic pathogens.

\section{References}

1. King AMQ, Lefkowitz EJ, Mushegian AR, Adams MJ, Dutilh BE, Gorbalenya AE, et al. Changes to taxonomy and the International Code of Virus Classification and Nomenclature ratified by the International Committee on Taxonomy of Viruses (2018). Arch Virol. 2018. http://dx.doi.org/10.1007/ s00705-018-3847-1

2. Spickler AR. Influenza. Flu, grippe, avian influenza, grippe aviaire, fowl plaque, swine influenza, hog flu, pig flu, equine influenza, canine influenza. 2016 [cited 2018 Mar 8]. http://www.cfsph. iastate.edu/Factsheets/pdfs/influenza.pdf 
3. Hause BM, Collin EA, Liu R, Huang B, Sheng Z, Lu W, et al. Characterization of a novel influenza virus in cattle and swine: proposal for a new genus in the Orthomyxoviridae family. MBio. 2014;5:e0031-14. http://dx.doi.org/10.1128/mBio.00031-14

4. Vemula SV, Zhao J, Liu J, Wang X, Biswas S, Hewlett I. Current approaches for diagnosis of influenza virus infections in humans. Viruses. 2016;8:96. http://dx.doi.org/10.3390/v8040096

5. Guo YJ, Jin FG, Wang P, Wang M, Zhu JM. Isolation of influenza $\mathrm{C}$ virus from pigs and experimental infection of pigs with influenza C virus. J Gen Virol. 1983;64:177-82. http://dx.doi.org/ 10.1099/0022-1317-64-1-177

6. Yuanji G, Desselberger U. Genome analysis of influenza $\mathrm{C}$ viruses isolated in 1981/82 from pigs in China. J Gen Virol. 1984;65:185772. http://dx.doi.org/10.1099/0022-1317-65-11-1857

7. Yamaoka M, Hotta H, Itoh M, Homma M. Prevalence of antibody to influenza $\mathrm{C}$ virus among pigs in Hyogo Prefecture, Japan. J Gen Virol. 1991;72:711-4. http://dx.doi.org/10.1099/0022-1317-72-3-711

8. Kimura H, Abiko C, Peng G, Muraki Y, Sugawara K, Hongo S, et al. Interspecies transmission of influenza $\mathrm{C}$ virus between humans and pigs. Virus Res. 1997;48:71-9. http://dx.doi.org/ 10.1016/S0168-1702(96)01427-X

9. Hause BM, Ducatez M, Collin EA, Ran Z, Liu R, Sheng Z, et al. Isolation of a novel swine influenza virus from Oklahoma in 2011 which is distantly related to human influenza $\mathrm{C}$ viruses.
PLoS Pathog. 2013;9:e1003176. http://dx.doi.org/10.1371/ journal.ppat. 1003176

10. US Department of Agriculture. Cattle and calves nonpredator death loss in the United States, 2010. 2011 [cited 2018 Mar 8]. https://www.aphis.usda.gov/animal_health/nahms/general/ downloads/cattle_calves_nonpred_2010.pdf

11. Gabinaitiene A, Siugzdaite J, Zilinskas H, Siugzda R, Petkevicius S. Mycoplasma bovis and bacterial pathogens in the bovine respiratory tract. Vet Med (Praha). 2011;56:28-34. http://dx.doi.org/10.17221/1572-VETMED

12. Bielefeldt-Ohmann $H$. The pathologies of bovine viral diarrhea virus infection. A window on the pathogenesis. Vet Clin North Am Food Anim Pract. 1995;11:447-76. http://dx.doi.org/10.1016/ S0749-0720(15)30461-8

13. Basqueira NS, Martin CC, dos Reis Costa JF, Okuda LH, Pituco ME, Batista CF, et al. Bovine respiratory disease (BRD) complex as a signal for bovine viral diarrhea virus (BVDV) presence in the herd. Acta Sci Vet. 2017;45:1434.

Address for correspondence: Jianfa Bai or Xuming Liu, Kansas State University, Veterinary Diagnostic Laboratory, College of Veterinary Medicine, 2005 Research Park Cir, Manhattan, KS 66502, USA; email: jbai@vet.ksu.edu or xmliu@vet.ksu.edu

\section{April 2014: Coronaviruses and Influenza Viruses}

- Distribution of Pandemic Influenza Vaccine and Reporting of Doses Administered, New York, New York, USA

- Regional Variation in Travel-related Illness acquired in Africa, March 1997-May 2011
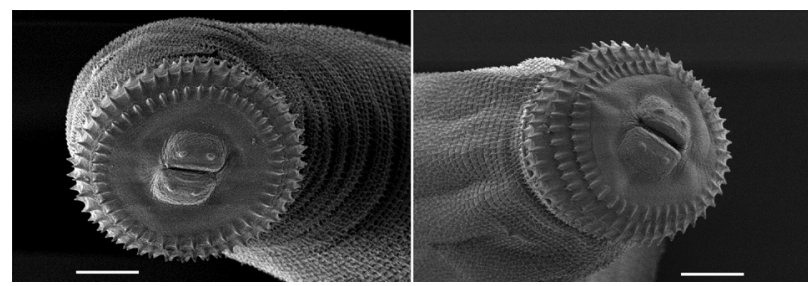

- Active Surveillance for Avian Influenza Virus, Egypt, 2010-2012

- Antibodies against MERS Coronavirus in Dromedaries, United Arab Emirates, 2003 and 2013

- Novel Betacoronavirus in Dromedaries of the Middle East, 2013

- Rotavirus Surveillance in Urban and Rural Areas of Niger, April 2010-March 2012

- Large Outbreak of Cryptosporidium hominis Infection Transmitted through the Public Water Supply, Sweden

- Efficiency of Points of Dispensing for Influenza $A(\mathrm{H} 1 \mathrm{~N} 1)$ pdm09 Vaccination, Los Angeles County, California, USA, 2009
- Underdiagnosis of Foodborne Hepatitis A, the Netherlands, 2008-2010

- Travel-associated Antimicrobial Drug-Resistant Nontyphoidal Salmonellae, 2004-2009

- Ciprofloxacin Resistance and Gonorrhea Incidence Rates in 17 Cities, United States, 1991-2006

- Contact Investigation for Imported Case of Middle East Respiratory Syndrome, Germany

- Rapid Increase in Pertactin-deficient Bordetella pertussis Isolates, Australia

- Gnathostoma spp. in Live Asian Swamp Eels (Monopterus spp.) from Food Markets and Wild Populations, United States

- Epidemic of Mumps among Vaccinated Persons, the Netherlands, 2009-2012

- High Rates of Antimicrobial Drug Resistance Gene Acquisition after International Travel, the Netherlands

- Characteristics of Patients Infected with Norovirus Gll.4 Sydney 2012, Hong Kong, China

- Pathology of US Porcine Epidemic Diarrhea Virus Strain PC21A in Gnotobiotic Pigs

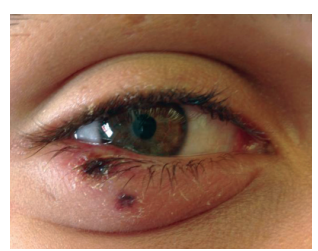

- Cetacean Morbillivirus in Coastal Indo-Pacific Bottlenose Dolphins, Western Australia 